\title{
Tick Tock Goes the Clock: Rethinking Policy and Embryo Storage Limits
}

\author{
Anita Stuhmcke
}

Published online: 11 December 2014

(C) The Author(s) 2014. This article is published with open access at Springerlink.com

\begin{abstract}
Cryopreservation of human embryos remains, in many jurisdictions, a critical component of the use of the technology of in vitro fertilisation (IVF) in assisted reproduction. However, although the reasons for the freezing of reproductive material - such as cost effectiveness and reducing risks of IVF-are a constant across jurisdictions, the desirable length of storage remains subject to ongoing regulatory debate. Internationally embryo storage limits are variable. This article features data from a recent Australian research project which explores individual attitudes, desires and understandings of law of IVF patients (and their partners) who had or who have embryos in storage. This article uses interviews from the study to argue that storage limits, like any apparently neutral regulatory tool, apply unequally causing unintended physical, mental and emotional harm - particularly to women. This analysis of storage limits exposes the interaction of time, science and law to create, apply and enforce norms and practices of 'natural' embryo storage, suggesting that the imposition of inflexible legislative restrictions upon embryo storage are socially contingent and value laden rather than 'natural' or 'scientific'. This outcome has relevance to wider debates over assisted reproduction policies, suggesting that legal frameworks should adopt more flexibility in application to the patients who use this technology.
\end{abstract}

Keywords ART · Embryo · IVF · Law · Reproduction · Storage · Technology $\cdot$ Time

\section{Introduction}

The imposition of legislative time limits for embryo storage was developed as policy in Australia in 1982, over 30 years ago. The first global pregnancy from a 'preserved'

\footnotetext{
A. Stuhmcke $(\bowtie)$

Faculty of Law, University of Technology, Sydney, PO Box 123, Broadway, NSW 2007, Australia e-mail: anita.stuhmcke@uts.edu.au
} 
embryo occurred in Australia in 1983 (Trounson and Mohr 1983). Concurrently the earliest law reform inquiries into in vitro fertilisation (IVF) raised the issue of freezing of reproductive material as a cause of concern. For example, the Warnock Committee in the United Kingdom (UK) observed that while there was no medical issue with the long term storage of embryos, that “...[S]erious legal complications may well arise, for example in relation to inheritance and the use or disposal of frozen semen, eggs and embryos" (Report of the Committee of Inquiry into Human Fertilisation and Embryology 1984, 10.4). The Committee recommended a 10 year storage limit for embryos. Earlier, in 1982, the Australian National Health and Medical Research Council (NHMRC) also recommended a 10 year limit, the justification being that the duration of embryo storage "...should not be beyond the time of conventional reproductive need or competence of the female donor" (NHMRC 1982).

Just two years on, Australian authorities were forced to confront both these alternative truths - of indefinite storage and reproductive use by others. In $1984 \mathrm{Mr}$ and Mrs Rio died in a plane crash, leaving their frozen embryos, without instructions for their disposition, in storage in Melbourne, Victoria. The embryos had been in storage since 1981. In the resulting confusion as to how the 'orphaned' embryos should be treated, complicated by the fact that $\mathrm{Mr}$ Rio was not the biological father, the Victorian state law reform inquiry recommended a shortening of the embryo storage limit period from 10 to five years. It did so on the basis that "... storage shall be for as short as periods as possible in terms of the reason for the storage of that embryo or those embryos" (Committee to Consider the Social, Ethical and Legal Issues Arising From In Vitro Fertilization 1984, 2.14). The underlying policy assumption being that short storage limits may prevent an embryo being left 'orphaned'. The same law reform body recommended that the Rios' embryos be destroyed. The Victorian Government, responding to community opposition, subsequently determined that the embryos should not be destroyed. The issue of the Rios' embryos was reportedly dealt with through donation to another couple where the implantation failed (DeMarco 2009).

Today, three decades on, while the length of storage limits do vary between international jurisdictions (Bankowski et al. 2005) the 10 year limit is still afforded substantial medical and scientific approval (Michelmann and Nayudu 2006; Mandelbaum et al. 2011). In Australia, the 10 year limit remains the norm across most jurisdictions (Millbank et al. 2013, 99). Similarly in the UK the Human Fertilisation and Embryology Act 1990 (as amended by the Human Fertilisation and Embryology Act 2008 s. 14(4)) (HFE Act 1990) permits a statutory storage period of 10 years maximum. However, special rules allow for extended storage in successive 10 year periods up to a 55 year maximum for individuals who are prematurely infertile (Explanatory Memorandum 2009).

Across the field of human reproduction legally imposed time limits vary widely. This reflects the fact that the legal response to the 'pre-birth entity' is a pragmatic one which differs according to the regulatory purpose and policy of a particular legal area (Stewart and Stuhmcke 2007). The imposition of legal time limits is tethered to any number of motivating factors. For example, similarly to embryo storage limits, the 14 day rule with respect to embryo research recommended in the 1980 s by the Warnock Committee is a fairly arbitrary time limit, widely adopted 
and unchallenged since the 1980s. It is generally accepted that the Committee took a pragmatic middle path between the range of views whereby the human embryo is a person from fertilisation and the other extreme whereby the human embryo is tissue like any other (Parliamentary Office of Science and Technology 2002).

With respect to embryo storage limits the 10 year limit is also a pragmatic response to an interplay of factors. These include the difficulties of longer term storage for clinics such as administration and costs (Brzyski et al. 2000; Magli et al. 2008) as well as the legal policy goal of creating certainty around embryo formation and disposition. While acknowledging these factors I wish to underscore here the significance of the reproductive purpose of the embryo to the policy of 10 year storage limits. This focus departs from that of examining policy debates surrounding the nature or image of the embryo (Mulkay 1994; Provoost et al. 2012) and does not attempt to reflect, except incidentally, upon what the embryo is or should be, which would draw in issues such as models of embryo adoption versus donation (Blyth et al. 2011; Bianchi 2011) and the use of embryos in research (Robertson 1990; Jackson 2006). Rather I draw upon historical policy to identify reasons for the imposition of a 10 year storage period. I do not attempt to provide a full explanation as to the policy debate with respect to stored embryos. Instead, my aim is to select the central concept of using the embryo for reproduction from the complex and layered policy issues which occur over storage. I then question the underlying justification of linking storage duration to reproductive purpose.

I argue that this policy approach ignores the needs and desires of IVF patients, in particular those of the women who created the stored embryos. Legal storage limits are almost universally applied from the point of the medical freezing of the embryo, with time usually ${ }^{1}$ running from the date the embryo is stored. Upon expiration of the storage limit the individuals responsible for the embryos are required to make a choice with respect to disposition (Lanzendorf et al. 2010; Fuscaldo 2005). This choice may result in the destruction of the embryo, either with it being allowed to succumb or donated to science for research use, or in rarer instances being donated for the reproductive use of others (Ellison and Karpin 2011). These options arise due to the 10 year and under time limit being aligned with what is 'natural' and 'necessary', meaning the use of the stored embryo for reproduction.

Of course there are further instances where factors other than storage limits operate to make the IVF journey painful and protracted. Here it is important to observe that not all women are the same and that not all experiences are tethered to the duration of storage. For example, disputes over the use of embryos may impact more upon personal experience than the setting of relatively inflexible storage time limits by legislatures (Annett 2006).

Also, storage limits are reinforced by the broader legal constructions governing the use of the embryo in the IVF process. Policies which promote the importance of the reproductive purpose of the embryo are to be found in the broader framework of IVF regulation such as through imposing age limits upon access to IVF or criminal record checks for individuals using such technology. Here the use of the legal

\footnotetext{
1 There are exceptions such as where an embryo is created with donated gametes. In such cases the storage period will generally run from the time of the gamete donation.
} 
framework of consent provides a clear case in point as the law prioritises genetic reproduction even allowing the gamete provider to veto reproduction in certain circumstances (see for example Schedule 3 of the HFE Act 1990 (UK) and Evans $v$ Amicus Healthcare Ltd and Others [2004] 3 WLR 681; [2004] 3 All ER 1025; see further Sheldon 2004). This broad legal framework thus reinforces the construction of the stored embryo as being created for reproductive purposes, reinforcing the justification for 10 year and under storage limits and removing the space for policy debate over alternative or more flexible time frames.

I use interview data drawn from the experiences of IVF patients responsible for embryos in storage, to identify alternative diverse and nuanced human connections to the stored embryo. These personal narratives, extracted from interviews undertaken in a recent Australian study ${ }^{2}$ expose the narrow construction of the reproductive purpose of the embryo which underscores parliamentary policy. I seek to demonstrate how the inflexibility of this discourse constrains, and may even obstruct, the decision making options of IVF patients, particularly women, who bear responsibility for stored embryos. Indeed in the wider study most participants preferred no storage time limit at all, or alternatively one based on a patient's need or ability to use the stored embryo(s) during the IVF recipient's lifetime or embryo viability or completion of their family (Karpin et al. 2013).

In juxtaposing the parliamentary policy of law with the lived experience of IVF patients, I borrow from both a long tradition of feminist legal scholarship, which focuses upon giving greater attention to situation and context, and not ignoring individualized circumstances for the sake of abstract justice (Bartlett 1990; Haraway 1991), and the field of Science and Technology Studies (STS), which contextualises the interaction of law, science and technology (Jasanoff 2012). While my focus is largely upon Australia and on embryo storage, the broader claims I make-that policy in this area both creates and reinforces a particular purpose of a stored embryo-should not be restricted to this jurisdiction. Across assisted reproductive technologies (ART) there are numerous sites of tension between science and nature. These are often disguised or displaced by legal policy, which acts as a powerful cultural agent to reinforce what is natural (even when it is not). The broad applicability of the perspective offered here is to advance understanding as to how values, power and culture are used by legal policy to create an inflexible regulatory regime which may displace, ignore and even harm the lived reality of individuals.

\section{The Reproductive Purpose of the Stored Embryo}

Policy justifications for storage limits are not based upon medical necessity. Indeed there is no scientific necessity for storage limits. The duration of storage has no

\footnotetext{
2 The study was undertaken by three investigators from the Faculty of Law at the University of Technology, Sydney: Jenni Millbank, Anita Stuhmcke and Isabel Karpin (with Eloise Chandler). Ethics approval was through the University of Technology, Sydney, Human Research Ethics Committee (UTS HREC Reference Number: 2009-262A). For findings related to the broader study, see Special Issue: Law, Policy and Practice Concerning Stored Embryos in Assisted Reproduction. 2013. Journal of Law and Medicine 20: 701-711, 759-830. The full report may be found at http://www.allabouttheembryo.net/.
} 
impact on the rates of implantation, clinical pregnancy, miscarriage or live birth rates (Riggs et al. 2010). An embryo may be effectively frozen for an unknowable time period. As Go et al. note, what 'constitutes 'long term' storage may elude definition" (1998, 2971). In 2011 a live birth was reported, some 20 years after the embryo was frozen (Dowling-Lacey et al. 2011) and "[A]nimal studies and theoretical modelling speculate that a frozen mammalian embryo should not be influenced by storage time for several thousand years"(Riggs et al. 2010, 109).

The policy justifications for storage limits are non-medical. Time limits of 10 years and under are presumed to be in the social, political and economic interests of IVF patients and wider society. While there are "very few explicit justifications for storage limits" (Karpin et al. 2013, 821), the central historical policy justification is to link the embryo to the reproductive capacity of the individuals responsible for storage. This policy reason is evident internationally-across continental Europe (Bangsboll et al. 2004) as well as in the UK and Australia. The aim being to ensure that the decision making process about the embryos remains with the couple that produced them, to link the embryo to the reproductive age of the individuals (particularly the woman) responsible for the embryo, and to ensure that decisions are made within what policymakers construct as a universally applicable timeframe for reproduction.

As noted above, this policy originates in the early 1980s, being traceable to the earliest law reform inquiries which touch upon embryo storage. It has been ever present since that time. Law reform inquiries across four Australian jurisdictions in the 1980s (NSW, South Australia, Queensland and Victoria) repeatedly refer to the reproductive purpose of the stored embryo as being central to questions of storage duration. For example, in 1988 the NSW Law Reform Commission in its Artificial Conception Report: In Vitro Fertilization recommended an initial limit of 10 years. Reasoning that the 10 year storage period would prevent the complexities which may follow from the imposition of a longer storage period such as the possibility of gamete provider's deaths or relationship breakdowns (NSW Law Reform Commission 1988, 5.46).

This early approach of framing storage limits with respect to the reproductive use of the embryo continued in Australia for the next three decades. In 1995 Australian clinicians from the Royal North Shore Hospital and Sydney IVF stated that the 10 year time limit "... was based on the presumption that if the woman was 40 at the time of the initial treatment, 10 years later she would be 50 and presumably would not desire embryo transfer later than that" (Saunders et al. 1995, 3081). A more current example is seen in the policy justifications offered in the Australian jurisdiction of Western Australia, whereby requests for extension of embryo storage must be tied to "probable future implantation" (Western Australia Reproductive Technology Council 2010, 2). Indeed the Human Reproductive Technology Act 1991 (WA) allows the creation of human embryos only for the purpose of achieving pregnancy in a woman. Under this Western Australian legislation there is a maximum storage period for embryos of 10 years, however, an application can be made by patients to the Reproductive Technology Council (RTC) for permission to extend storage for longer periods (Human Reproductive Technology Act 1991 (WA), s 24(1) and Human Reproductive Technology Act 1991-Directions (2004) (WA) 6.10-6.12). In 2012 the Western Australian authority granted all 16 requests 
for storage extensions of embryo storage (Western Australian Reproductive Technology Council 2012, 12). In granting these requests the Council acknowledged that "...it can be difficult for people to reach a decision regarding their stored embryos" (Western Australian Reproductive Technology Council 2012, 11). The RTC policy notes that all storage extension requests must take into account both the "prospective welfare of any future child" the "welfare of the person requesting the extension" and the "equity, welfare and general standards prevailing in the community" (Western Australian Reproductive Technology Council 2012, 4).

This focus upon the child exposes storage limits as one component of a wider legal narrative of family creation and formation with respect to ART. The law normalises medicine and technology in this area through 'cherry-picking' from a range of traditional legal areas to reflect and project dominant norms of human reproduction. For example, the welfare of the future child embeds norms of family law while storage limits center medical concepts of autonomy to promote clarity in IVF patient decision-making and assistance in reproductive opportunity. Thus the use of consent, both a contractual and medical concept becomes incorporated into this larger framework of regulation as it has been suggested that shorter storage periods increase the likelihood that written consent forms validly represent patients' wishes (as they are more recent) (Law and Ethics Taskforce of the European Society for Human Reproduction and Embryology 2001, 1049).

Changing the duration of storage limits by and of itself will not resolve issues as to the use of ART for all women. Without introducing flexibility of regulation and simultaneous change to laws surrounding issues such as consent, dispute resolution and posthumous reproduction (to name but a few), this will remain an area of legal regulation which fails to prioritise the needs and desires of IVF patients, both women and men.

However the analysis of the interviews in the study below suggests that introducing more flexibility into storage duration is desired by IVF patients. It is here that the broader investigation arises as to whether flexibility in the regulation of assisted reproduction is a preferred model for policy formation over the current inflexible approach of treating all individuals and embryos the same. The remainder of this article argues that far from promoting reproductive opportunity the current storage limits obstruct, curtail and even deny IVF patients, particularly women, the use of their stored embryos for reproduction and alternative purposes such as protecting against an unknown future or imagining a future family.

\section{What Happens When the Reproductive Purpose is not Achieved?}

Parliamentary policy embodies and projects powerful norms as to how 10 year storage limits facilitate reproductive opportunity. However, in reality storage limits also act simultaneously to both deny autonomy over reproduction and choice of embryo disposition, thus restricting reproductive opportunity and autonomy. Most obviously this is the case in the compelled destruction of an embryo. While far from uniform, the general approach in Australian jurisdictions is one of when the time limit is reached the embryo must be disposed of - whether or not this accords with 
the wishes of the IVF patient (Stuhmcke and Chandler 2014). Such destruction is framed in public policy as being in the interests of society and patients. For example in 2011 the Western Australian RTC states in its storage policy that "Indefinite storage of embryos is arguably not ethical, and does not assist participants, many of whom are repeat applicants, to resolve their issues concerning their stored embryos" (Western Australia Reproductive Technology Council 2010, 2).

This binary operation of storage limits, acting to both promote and deny reproductive opportunity, exposes the pragmatism of ART policy. Ten year and under storage limits reflect the role clinics play as storage facilities (Scott et al. 2012) through largely removing the 'problems' created through long term storage (Veeck 1997). Such problems include difficulties of administration and payment of fees, given that the economic model of embryo storage is that those responsible for creating the embryo pay for storage. The imposition of short storage limits also claims to reduce 'abandoned' embryos. This policy motivation was implicit in the early 1980s reaction of the Victorian Government in the case of the Rios when the storage limit was reduced from 10 to 5 years; the shorter the time frame the less likely embryos will become 'orphaned' (Committee to Consider the Social, Ethical and Legal Issues Arising From In Vitro Fertilization 1984, 2.14).

Thus, as previously noted, the 10 year and under storage limits are the result of an interplay of aims which exist apart from reproduction such as they may also exist to ward against patient carelessness, forgetfulness, or inability to decide on disposition. For example, IVF clinicians Ben-Ozer and Vermesh report the birth of a healthy full-term boy following the transfer of embryos stored for seven and a half years, stating that "Our patient forgot that she had frozen embryos" (Ben-Ozer and Vermesh 1999, 1651). Storage limits serve a social purpose and link the embryo to the individuals who created it, either legally or biologically. Presumably to be able to ensure that any resulting child is born within an immediate economic and social kinship network-where there is a biologically, socially and temporally understood mother or father or parent.

This underlines the complexity of storage limit policy. The policy has multiple layers of economic, social and political aims. Ten year limits on storage exist not just to promote reproduction but also to prevent ethical conundrums and slippery slopes. These include avoiding the difficulties inherent in the debate over embryo abandonment and accumulation (Thomas 1997-1998) and limiting debates about the marketization of the body including economic costs and storage fees (Connolly et al. 2010). Of course the 10 year storage limit may not solve all conundrums, such as the 1980s case of the Rios, who died millionaires and the consequent legal debate as to embryo estate planning and inheritance (Lorio 1996). However the 10 year storage limit is nevertheless useful in circumscribing much of the discourse in this area of law. The forced destruction of embryos, besides promoting reproduction, thus acts to constrain the depth and range of issues which storage raises, as diverse as ownership of embryos as property (Bennett 2000) through to whether the embryo has 'rights' (Mulkay 1994).

Ironically this pragmatic approach of setting 10 year and under storage limits actually results in social, legal, ethical and economic dilemmas and conundrums. IVF technology replaces the conceptive process (Franklin 2006, 552). As Augst has observed "[T]echnology simplifies models of reality, or of causality and effect, to 
be able to control and function in different environments.... The very rationality of technology can lead to highly irrational results" (Augst 2000, 222). This irrationality is present as storage limits create significant and largely irresolvable societal issues. Storage limits give rise to dilemmas which otherwise would not exist, such as the mass embryo destruction which occurred in the UK in 1996 when 3000 frozen embryos were destroyed once time had exceeded statutory storage limits (Rosenwaks and Davis 1997; Kuo 1996-1997).

\section{The 'Journey' of the IVF Patient and Their Stored Embryo(s)}

These dilemmas underscore embryo storage as not a 'usual', 'normal' or 'natural' occurrence. Embryo storage displaces lineal time, natural reproductive processes and normative understandings of family creation. Although time is inescapable (Greenhouse 1989, 1631), temporal reality is altered forever through embryo storage. This fact is ignored by parliamentary policy which sets 10 year storage limits to replicate 'natural' reproductive ageing.

Universal storage limits categorize all embryos as 'the same'. In this sense policy is focused upon the community expectation of the practice-frozen at the point of embryo creation - rather than the evolving or ongoing desires and needs of IVF patients. Policy debate centralises a particular normative reproductive aim of IVF, according to traditional notions of kinship and family.

The nature of the IVF journey and how constructions of the embryo may change for persons responsible for embryos during storage is well documented. There are multiple trigger points where storage becomes its own journey, separate from the IVF process, such as when a family is complete or once a time limit is up. This is evidenced by international studies on embryo storage which focus on why and how individuals make decisions about their stored embryos (Nachtigall et al. 2005; Bankowski et al. 2005; Lyerly et al. 2008), what decision they make (Lanzendorf et al. 2010) and whether they change their minds as to their disposition options throughout their period of treatment (Klock et al. 2001). While many of these studies are survey based (or interrogate clinical data) there is growing interest in investigating qualitative dimensions (Lyerly et al. 2006; Nachtigall et al. 2009). In Australia there is a small number of existing studies which address the actual experiences of the decision making process for those individuals who are or have been responsible for stored embryos (de Lacey 2005; Kirkman 2008). Such studies demonstrate that decision making about embryos is a dynamic and emotional process which is often both painful and protracted (de Lacey 2005, 2013; Nachtigall et al. 2005). This is not surprising as individuals with embryos in storage did not begin the process with that end in mind and are often unprepared for this eventuality.

\section{The Methodology of the Australian study}

The interview material I draw upon forms part of the most recent Australian study undertaken with two of my colleagues into embryo storage which collected data from July 2010 to July 2012 (Millbank et al. 2013). The study utilised a multi- 
method recruitment process, using both clinical avenues and broader advertising to the public. It drew responses from all Australian jurisdictions (except the Northern Territory). The goal of the study was to enhance reproductive opportunities by helping to craft flexible laws, policies and practices around Australia-where seven different legislative regimes govern assisted reproductive technology. One of the aims of the study was to explore the impact of storage limits upon IVF patients responsible for embryos. Individuals were therefore asked questions such as what they understood the time limits to be and what they thought of such limits.

Questions were targeted but aimed to elicit as much additional information from participants as possible. The study is comprised of 349 completed written surveys. The interviews, discussed below, are a sub-sample of those who participated in the survey. Semi-structured in-depth interviews took place with 54 participants in total: 48 interviews were conducted with individual participants and the remaining three were conducted with both members of a couple. The written survey was used to gauge broad trends and the in-depth semi-structured interviews used to explore participant views and reasoning. The data was subject to thematic analysis. All interviewees are represented by a pseudonym.

In common with most empirical research on fertility (Access 2008), the participants in the written survey were overwhelmingly female $(\mathrm{n}=387,96 \%)$; 16 were male (4\%). Participants were generally aged between 31 and 40 years old. The largest cohort, $36 \%$ was between 36 and 40 years old $(n=143)$; followed by those between 31 and 35 at $29 \%(n=115)$. The next largest groupings were in the $40-50$ age range: those between 41 and 45 comprised $18 \%$ of participants $(n=74)$; and those between 46 and 50 were $11 \%(n=25)$. While the majority of participants had used their own gametes, around one third were recipients of donated gametes or embryos. The most common length of storage (33\%) was 1-2 years. Of the remainder, $26 \%$ reported having their embryos stored for 2-5 years, $21 \%$ for six months or under, $15 \%$ for 7-12 months, and $6 \%$ for over five years.

Among the sub-set of 48 interviews, over two thirds of interviewees were in heterosexual de facto relationships or married at the time of their IVF treatment (70 \%, $\mathrm{n}=38)$. The remainder were in lesbian de facto relationships $(17 \%, \mathrm{n}=9)$ or were single $(13 \%, \mathrm{n}=7)$. Most interviewees were female $(83 \%, \mathrm{n}=45)$. Of the nine interviews conducted with men $(17 \%)$ : seven were interviewed individually and two in joint interviews with their female partners.

The in-depth interviews sought to explore more deeply and spontaneously than the written survey whether survey participants understood that there were storage limits and whether they could identify the source of these limits. In particular, information was sought as to the level of awareness of storage limits being imposed as a result of state law, the Australian National Health and Medical Research Council (NHMRC) Ethical Guidelines or clinic policy. In particular the interviews examined the lived reality of the impact of legal storage limits, revealing that the impact of embryo storage is intensely personal, constantly evolving and multifaceted. The interview data is not available to the wider public. The analysis that follows is made possible by my access to this data based upon my being a member of the research team. Much of the interview data on storage limits reinforces the general findings of the larger study (see Millbank et al. 2013). 


\section{The Interviews: Fractured Time and the Reproductive Purpose of Storage Limits}

It is seemingly trite to observe that the passing of time is central to storage limits. As discussed previously the policy of linking the reproductive purpose of the embryo to storage duration is based upon reproductive age and ensuring those who created the embryos use them for the purpose of family creation.

However storage limits also serve a political purpose. They ensure that cryopreservation is not 'tearing apart' existing social arrangements as to 'natural and moral' reproduction (Jasanoff 2004). This is made necessary as the reality of cryopreservation of embryos is to replace lineal time for many IVF patients. As Franklin states "the logic of IVF also displaces the very certainty of the processes it affirms" $(2006,550)$. The reality of embryo storage is to break connections between past, present and future. Indeed, incongruity arises as the law enforces a passage of time for an embryo yet the practical result is that storage limits fracture time, suspending time for the embryo but not for the individuals who have storage responsibility. This in turn results in disruption between genetic and social parenthood and creates tensions for how future relationships between all parties was envisaged (Goedeke and Payne 2009, 5).

This fracturing of time is apparent amongst interviewees. For example Bridget, who has teenage twins through IVF, donated her remaining embryos to another infertile couple who had two children from them. While the resulting four living children are now different ages, Bridget observes that "..they refer to themselves as the quads because they were all conceived on the same day." Thus despite the children in the present being 4 and 6 years apart in age they describe themselves as locked together forever in a temporal present. Bridget's children deny lineal time. The lived reality of embryo storage is that these four children actively choose to embrace fractured time. The children converge the past, the present and the future and deny calendric ageing between the four of them.

The policy justification of tying embryo storage time to the reproductive age of those responsible for storage both reframes and restrains this disruption of time. This is reflected by an interview with Marcus. Marcus, the father of one set of twins and a daughter born through IVF, states:

...the storage thing also links with the age of people. Well because if you start having IVF in your mid-thirties as lots of people do. If those little dudes have been in there for 10 years and the person who is going to be giving birth to them is now 45, I don't know how-at what point do we say-people need to be able to play with their kids. They need to be able to do stuff with their kids. If they're 50 when their kids are born, there's issues about that. So the two things are linked really.

Marcus thus echoes the policy justification linking: the raising of children; age; and the 10 year storage limit. Similarly, Roger observes that,

...I wouldn't like to think that you'd leave your embryos in storage until your children finish secondary school or have a brood of their own before you said 
well we might do something with them now. I wouldn't like to think they stayed around that long... what do you do with them at that point? You know you are probably too old then to do anything about it and your only choice is to donate. In which case you would have been far better off donating many, many years earlier.

As Marcus and Roger confirm, storage limits apply time to cohere with the wider world of what is 'natural' in reproduction and what is said to be objectively necessary in ART treatment in science and technology. ${ }^{3}$

\section{The Interviews: Time, Law and Pain}

Storage limits are not a value-neutral regulatory tool. Tying the value of the embryo to human reproduction is a political outcome rather than one which is predicated upon scientific need. As Munn observes "control over time is not just a strategy of interaction; it is also a medium of hierarchic power and governance" (Munn 1992, 109). From the interviews with IVF patients we can see the power and the disingenuousness in how the legal application of calendric time (Hallowell 1937) operates to deny the scientific reality that a stored embryo has no age.

Time and law thus combine to coordinate the embryo into a system with particular values and powers. For example Pam, an interviewee who is 47 and has had six embryos in storage for 10 years states "I think the decision is going to be made for us actually, because come late September, they're 10 years old and so I don't think we can donate them, because they will be too old". In giving her embryos an age Pam confirms the normative power of the social and political 'truth' of storage limits. The embryos are not 10 years old. Indeed the medical and scientific reality is that her embryos will never grow 'old'. Yet here the result of reproductive policy is for Pam to construct her own embryos as both 10 and 'old'.

Storage limits are powerful, socially contingent and value laden. As such their imposition may cause enormous personal pain. Time on a clock may be "empty, uniform and linear" (Harrington 2012, 493) but with respect to embryo storage it acts as a significant organising power in what are highly personal decisions concerning reproduction and family formation. As Jasmine observes:

But the thing is the government orders that they be destroyed when they turn five. The first one turned five about two weeks ago and that was the last one from the first batch. So that was destroyed two weeks ago which was a pretty horrible process for me. I was-I ended up in hospital because it was so devastating that I just didn't cope with it...

Similarly to Pam, Jasmine observes that her embryo has 'turned five', like a child. Jasmine has five embryos in storage and is engaged in a dispute over the embryos with her partner. Her experience exposes storage limits as neither neutral, beneficial

\footnotetext{
${ }^{3}$ While this study has interviewed more men than any other it is not possible to say whether these views expressed by two men evince a different attitude/relationship towards embryos/children from women.
} 
nor necessary; but rather, as harmful and dangerous. Jasmine spent a week in hospital following the destruction of her first embryo and observed that:

I still haven't dealt with it yet. It's still kind of really hurts and I get upset about it. Knowing I've got to go through this process again in October when the rest of them-the other turn four and five-is really quite stressful.

Jasmine's experience confirms that personal pain is greatly exacerbated when the conclusion of storage or the destruction of the embryo was not a result of their own choice or at a time of their own readiness (Karpin et al. 2013).

Some interviewees reject the policy of reproductive purpose of an embryo. For example, Clarice makes reference to the illogical place of law in governing temporality in this area:

If technology allows you to make those reproductive choices at any age, then I don't see at all why you shouldn't avail yourself of those. If it's not to do with the embryo viability, the only other possible sort of upper time threshold must relate to the age of the parents at the time they use them. I don't think the law has a place in that.

Interestingly Clarice contacted her clinic at the 10 year point of storage of her three embryos and was told that she could keep her embryos indefinitely as long as she paid her storage fees. Clarice says that "I guess I am expecting that situation to go on indefinitely". Here the juxtaposition of Clarice's rejection of the role of law in setting storage limits and Jasmine's pain in having the limit imposed is reflective of the controlling power of time. In Clarice's case she has been assisted by the clinic to reject the application of time and therefore, perhaps unsurprisingly, is able to comment on the lack of place for the law in her decision making whereas Jasmine has had the alternative experience. Conversely, Jasmine has experienced the powerlessness and lack of control brought about through the application of time and law with respect to her stored embryos.

\section{The Interviews: The Unequal Application of Universal Storage Limits}

Storage limits effect different women (and men) differently. The experiences of Jasmine and Clarice evidence how universal storage limits apply unequally. Here, as Bartlett explains in her discussion on feminist legal methods, the 'woman question' may be asked to expose how storage limits apply differentially with respect to age and gender (1990). An interviewee, Ruby, confirms the differential impact of storage time limits as pertaining to the individual who takes on the primary care giving role:

I feel like I've been in this tunnel of young children-it's a dark, dark tunnel with no end to it and I'm just coming out of that and I'm starting to go: Oh, right. I need to think about some other things like is the big girl going to private school or what am I going to do about embryos; more than just the day to day stuff and try to think about the bigger issues now.' ...' for me it's that 
period of time, it's when a woman can think clearly again and stop focusing on trying to get pregnant and have a baby.

At the time of the study Ruby had three children - aged nine, three and one. Embedded in Ruby's comment is recognition of the all-consuming role she has played in raising her children. In Ruby's case the 10 year storage limit for stored embryos is relatively short given the spread of age for her children. Ruby expresses the importance that for her, any decision to be made about her remaining embryos is a serious one which should not and cannot be made without account of her personal needs.

Ruby's position raises the more general issue as to the impact of storage limits upon the more time restricted reproductive opportunity for women. Chloe, with one embryo in storage, states with respect to her stored embryo and disposition that "[W]omen are saying no, its more than that, its an emotional thing" and "I think a woman has to be mentally and emotionally ready to make that decision...". For Chloe her remaining embryo is the "closest thing" she has to having a child and she is unable to let go of the embryo for that reason. Similarly, Alice who is married with two children conceived through IVF and who opted to destroy her remaining embryos, when asked about how long people should be able to store their embryos responds:

It depends upon people's ages and stuff. I don't know if I'd feel that comfortable about a 60 year old going off and doing it but yes, as long as it kept doors open for people. Different people have different circumstances in life and I don't think they should have this one set rule without taking into account other factors and influences. Every case is different.

Alice raises two conflicting yet complementary points. That on the one hand storage limits may, due to reproductive age, deprive individuals of the opportunity to reproduce as and when they wish to and thus deprive women more quickly than men of the creation of future family. And, on the other, that storage limits are tangential not upon the reproductive ageing of the individuals responsible for them but also upon their life stages.

\section{The Interviews: Embryos are not All Alike}

A cornerstone of policy in this area of ART is to treat all embryos alike. The interviews reveal that "[E]mbryos are not all alike, and neither are their identities singular" (Jacob and Prainsack 2010, 505). Individuals understand their embryos differently. Some view their stored embryos as not "yet part of a family that might have moved through time without them" (Roberts 2007, 192), where the embryo is relational to the planning of the future family and the desired time gaps between children. Others have desires which directly conflict with this policy objective in that they want to keep the embryo for future use for a purpose for which it was not created. This is explained by Juliet who has one embryo left in storage:

I wanted to have it as a like a-something in the like the library, in the safe or whatever just in case something goes wrong with my family. So I didn't want to donate it for research. I kind of thought I could use-or my family, or my 
children could use it for something if the technology caught up with things in another 20 years or something like that.

This conceptualisation of unknown future possibilities is echoed by Analise, who had just signed the paperwork to discard her remaining embryo. Analise felt that had it not been for the storage fees she would have continued to store the embryo indefinitely,

Yes, I think I would prefer to leave it just sit there-you know-because eventually the research option would have come up-even if it is 20 years of something, someone at some stage would have-sooner or later I think it would have been an option-so if I didn't have to pay to keep it there that long then I probably wouldn't have ...

And further on

This is the thing - there's no research to tell you that it's useless after 20 years or it's useless after seven years or-no one can tell you that and-someone donates a 20 year old embryo to then thaw it and see-look that's never going to survive-or that could go on.

Policy constructs the embryo as a separate and dispensable 'object'. Not a scientific object, but rather a social object. The very reason for a storage limit is to force a change in status of the embryo, from being stored into becoming 'other' than stored. In this way storage limits preserve the scientific embryonic function as one of being a 'spare part' for the IVF procedure (Hogle 2001, 62-63). In the context of reproductive policy the embryo is a social object, useful only for the purpose of reproduction within a particular time. If not so used the embryo must be forcibly removed from people's lives.

This point is further made by Jess. Jess, in a lesbian relationship, has a son who was born through IVF using donor sperm who has Down's syndrome. Jess observes this positioning of the embryo as a social object when she describes how:

I feel like, even now, the embryos are just sort of like a side issue, when we talk about or talk to the clinic. It's all about our child and any potential children, rather than the protection of the embryos.

Ironically, even though the stored embryo is the focus of storage, as Jess observes, it is a 'side issue'. As Jess observes, the objective of the embryo is characterised as one of reproduction, linking the decision to the reproductive age of the creators rather than any other objective. Notions of embryo protection, or alternative use of the embryo (such as indefinite storage), are thereby rendered irrelevant to normative discourse in this area.

\section{The Interviews: The Absence of Finality and Storage Limits}

Finally, it is important to observe that the policy justification of giving finality and certainty to IVF patients through linking reproductive to a 10 year time frame is 
refutable. Phoebe, a 43 year old woman had twins through IVF, who were aged 10 at the time of interview. After having the twins Phoebe and her husband decided they wanted to donate their stored embryos to research. The clinic declined this as an option. Faced with the destruction of her embryos by the clinic, Phoebe ultimately decided to physically remove her embryos from the clinic. This involved collecting the embryos and taking them home with her. At the time of interview her embryos were behind the butter in the fridge and Phoebe wants to bury them in her garden. Phoebe states:

... I'm just looking at this letter here. I think because I spoke over the phone to the embryologist as well and there was emails, but yeah it was like, well okay, choose a date and time. Basically, I made an appointment, walked in, sat for five minutes; they took me through when the embryologist was ready and signed forms and got a little specimen bag and a test tube, basically. It's still sitting in my fridge and I. Yeah, I haven't touched it. I know they're not viable, I know as soon as I walked out that door that was the end. I did after a while feel a relief sort of thing, it was all over, that I didn't have to worry about that any more. But now, like I said, they're still sitting in my fridge because I now don't know where-I know I sound like a fruit loop but I'm not. I don't know where to put them.

Phoebe expresses a 'relief' that the clinic storage is over. This reflects the policy justification of storage limits affording certainty and finality to IVF patients. As stated by the Western Australian RTC in 2011, storage limits assist IVF patients to make decisions and thus "...resolve their issues".

However in direct contrast with this finality offered by storage limits, Phoebe collects her embryos from the clinic at the end of storage and leaves them, "sitting in my fridge because... I don't know where to put them." Arguably Phoebe's experience of decision making at the end of storage pierces the policy veil of rationality, logic and dispassion of time limits. For Phoebe the decision making process does not finish at the end of storage. While she expresses relief at the finalisation of the clinic process she then places the embryos in an altered form of storage, and is still at the time of interview, coming to a decision as to when and what she will do. Phoebe's actions expose both the continuing uncertainty and the absence of finality storage limits have created for her.

Phoebe's personal difficulty of coming to a decision as to what to do when storage finishes is supported by earlier research. This research, both Australian and internationally, evidences that many people find the decision-making process particularly difficult and tend to delay making the decision as long as possible (de Lacey 2007; McMahon et al. 2000; Nachtigall et al. 2005). As Kovacs observes:

Frozen embryos are obtained at a great financial and emotional cost. It is well documented that the majority of couples have great difficulty coming to terms with the need to dispose of their excess frozen embryos. They often delay the decision; indeed they may find it the most difficult decision they have ever had to make. $(2003,128)$. 
This point was echoed by Phoebe:

... [the] embryos were happily sitting there in storage for a number of years. Then we got a letter to say that the status had changed and that they would no longer be looking at doing research for embryos. So then we were sort of put in a position of what do we do now? But every time you receive a letter about the status of your embryos, it's just emotional because it just makes you sort of think, oh, we've got to come to some decision, and we didn't want to do that.

Phoebe's experience raises the difficulty for policymakers in this area. In order to accommodate Phoebe's indecision the duration of storage limits must be indefinite-or subject to Phoebe reaching a resolution that may never occur. This raises the impossibility of a coherent policy justification to respond to people's needs and beliefs that are both diverse and complex.

\section{The Interviews: The Reason for a Policy of Inflexibility}

Rather than solving all individual desires the issue may rather be one of reviewing, refining and adjusting the policy assumptions surrounding embryo storage. As Jacqui observes:

It would be really hard to legislate because I think everyone's fertility or infertility journey is so different and so personal. It's an out of body experience in that you just don't really want to be going through it, but you are and you've taken a deep breath and you have to just go through that journey, and the journey needs an end which you have to be aware of. So [the question is] whether legislation would help some people create an end to it.

Jacqui captures the difficulty for the IVF patient of a 'one size fits all' approach. However her observation also confirms how unsurprising it is that the question as to whether policy can cope with different embryos differently situated as per the individual circumstance of those responsible for them has to date been ignored in the field of assisted reproduction.

Inflexibility in approach to regulation in this area is doubtlessly both easier and effective for policymakers. It allows fundamental questions to be ignored such as whether the practice of embryo storage is even necessary. This becomes most obvious in the recent innovations made in successful cryopreservation of oocytes. Despite the fact that in 2012, the process of cryopreservation of oocytes was no longer regarded as experimental in the United States (The practice committees of the American Society for Reproductive Medicine and the Society for Assisted Reproductive Technology 2013) little has been said about how long eggs may be stored for, despite the flagging of the hope over a decade ago that oocyte storage will render embryo creation and storage less relevant (Gook and Edgar 1999). 


\section{Conclusion}

Interviews from the study illustrate that the current 'one size fits all' restrictive policy approach in the area of ART is harmful. Individuals are diverse. Some believe their embryo to be a child, others (such as Chloe) desire to preserve their embryo indefinitely as representing a last remaining opportunity to have a child. While policy may not easily accommodate such rich diversity, it is hoped that steps can be taken to reduce overly prescriptive policies and thus increase responsiveness to patient needs.

Storage limits are one component part of the larger regulatory framework which governs assisted reproduction. The 10 year limit on storage is a supporting piece in the larger patchwork of policy regulation which aims to tether the stored embryo to reproductive purpose and in doing so, to restrain the 'unnatural' outcomes and challenging conundrums raised by this technology. Importantly the lived experience of people with embryos in storage shows the false and often very painful dichotomy between universal policy positing their embryos as 'running out of time' and the 'clock ticking', and their own diverse views as to the reality of the embryo within their present and future lives.

Linking embryo storage time to reproductive purpose, particularly to the timeframe of female reproduction, is normatively powerful. This is particularly clear when viewed against the absence of purpose for the embryo provided by the 'alternative' extremes of no storage at all or limitless storage.

In the absence of using alternatives to embryo storage, such as egg freezing, no embryo storage at all is unlikely. In jurisdictions such as the UK and Australia, where embryo storage is embedded in ART treatment an absence of storage is not viable, "..because cryopreservation increases the total reproductive potential of assisted reproductive technology (ART), expands therapeutic options, and improves treatment safety in patients undergoing ART, its use has increased dramatically" (Riggs et al. 2010, 109). This 'need' for storage of embryos is dependent upon cultural belief systems (Roberts 2011).

Similarly to no storage at all, the option of limitless storage is, at this point in ART history, undesirable. Limitless storage is characterised as serving no clear purpose for the embryo and gives rise to difficult legal, ethical and moral issues. The consequences of limitless storage are unknowable except by reference to the power of the narrative of storage limits. For example one such powerful inference is the apparent danger that limitless storage will pose in fracturing traditional notions of chronology and generation (Simpson 2006). The meaning of motherhood and fatherhood has always been geographically and temporally specific (Jackson 2008). The narrative of storage limits infers that limitless storage will negatively challenge assumed temporal convergence between 'mother' and 'father' and 'child' creating a more permeable distinction between the social and the biological (for example, postmenopausal motherhood made possible through IVF has been met with outrage (Cutas 2007)). Limitless storage challenges these notions in potentially preferencing other forms of kinship where biology may be only incidental to the making of relationships. 
A further inferred danger of limitless storage is the increasing numbers of embryos in storage across the world (Goedeke and Payne 2009). This is occurring across Western developed countries such as the United States and France (Michelmann and Nayudu 2006, 140). This is deemed undesirable due to the issue of embryo 'abandonment'. Policy justifications to date infer this will be exacerbated through removal of storage limits. However the evidential link between storage limits and preventing embryo accumulation is tenuous. Researchers have put forward reasons other than storage limits for the current levels of 'abandoned' embryos. For example, Lanzendorf et al. point to the inability of many clinics to offer embryo donation programs as prohibiting disposition choice (2010, 487). Wang et al. observe the importance of clinic policy in avoiding the accumulation of large numbers of embryos (1994). Provoost et al. note that it may be due to the patient's assumptions that the embryos had passed their 'use by date' or 'best before date', finding that patients may not contact the clinic with their disposition option as it will not serve any purpose as any decision is not useful in such circumstances (2010).

Between the above 'extremes' of limitless storage and no storage at all is a wideranging discretion as to time limits. In promoting the reproductive use to which the stored embryo should be put parliamentary policy renders alternative possibilities unnatural and undesirable. The power of policy is thus to transform both the displacement of lineal time caused by embryo storage and the scientific reality of the timelessness of a stored embryo into a normative framework which actively reinforces 'natural' family formation. However 10 year storage limits are not a panacea for the complex issues in this area. Not all IVF patients desire this length of storage and exceptions to time limits in legislative policy allowing extensions of time recognise that not all embryos are equal. By linking storage time to the reproductive purpose of the embryo, parliamentary policy acts to both mask the highly complex understandings of the passing of time as evidenced by individuals with stored embryos and to cause substantial distress and anxiety of individuals facing decision-making with respect to embryo disposition at the end of any storage period.

The point of this paper is to identify disconnect between scientific truths, IVF patient experiences, female reproductive opportunity, storage limit justifications and the application of time. It aims to highlight how unstated policy assumptions may operate across assisted reproduction to create inflexible, unequal and harmful legal regulation. Whether the current 10 year limit should be changed and what it should be changed to is beyond the scope of this paper, yet it seems that there is much room for debate concerning the normative assertion of nature onto a technological practice. Without such debate the tension and conflict created by forced convergence of reality, law, science and the application of time will never be uncovered and the future of ART in promoting reproductive opportunity, particularly for women, may be the poorer for it.

Acknowledgments Thanks to Jenni Millbank and Isabel Karpin for their thoughtful comments on earlier drafts and to Eloise Chandler and Janna Wessels for research assistance. Discovery Project (Grant No. 0986213) from the Australian Research Council and UTS: Law. 
Open Access This article is distributed under the terms of the Creative Commons Attribution License which permits any use, distribution, and reproduction in any medium, provided the original author(s) and the source are credited.

\section{References}

Access Australia. 2008. The utilisation and meaning of human embryos and eggs: A survey of access Australia Members.

Annett, Tim. 2006. Balancing competing interests over frozen embryos: The judgment of Solomon? Medical Law Review 14: 425-432.

Augst, Charlotte. 2000. Regulating dangerous futures: The German Embryo Protection Act of 1990Legislation in risk society. Social \& Legal Studies 9(2): 205-226.

Bangsboll, Susanne, Anya Pinborg, Claus Yding Andersen, and Nyboe Anders. 2004. Patients' attitudes towards donation of surplus cryopreserved embryos for treatment or research. Human Reproduction 19(10): 2415-2419.

Bankowski, Brandon, Anne Lyerly, Ruth Faden, and Edward Wallach. 2005. The social implications of embryo cryopreservation. Fertility and Sterility 84(4): 823-832.

Bartlett, Katherine T. 1990. Feminist legal methods. Harvard Law Review 103: 819-849.

Ben-Ozer, Snunit, and Michael Vermesh. 1999. Full term delivery following cryopreservation of human embryos for 7.5 years. Human Reproduction 14(6): 1650-1652.

Bennett, Belinda. 2000. The human embryo as property? Cryopreservation and the challenges for the law. Journal of Law and Medicine 7: 434-441.

Bianchi, Daniel. 2011. The adoption of embryos in Malta: Acting in the interest and welfare of a child in embryonic form? Medical Law Review 19: 401-429.

Blyth, Eric, Lucy Frith, Marilyn Paul, and Roni Berger. 2011. Embryo relinquishment for family building: How should it be conceptualised? International Journal of Law, Policy and the Family 25: 260-295.

Brzyski, Robert, Peter Binkley David Pierce, and Carl Eddy. 2000. Impact of implementation of an embryo storage fee on embryo disposal activity. Fertility and Sterility 74(4): 813-815.

Committee to Consider the Social, Ethical and Legal Issues Arising From In Vitro Fertilization. 1984. Report on the Disposition of Embryos Produced by In Vitro Fertilisation.

Connolly, Mark P., Stijn Hoorens, and Georgina M. Chambers. 2010. The costs and consequences of assisted reproductive technology: An economic perspective. Human Reproduction 16(6): 603-613.

Cutas, Daniela. 2007. Postmenopausal motherhood: Immoral, illegal? A case study. Bioethics 21(8): 458-463.

de Lacey, Sheryl. 2005. Parent identity and "virtual" children: Why patients discard rather than donate unused embryos. Human Reproduction 20: 1661-1669.

de Lacey, Sheryl. 2007. Patients' attitudes to their embryos and their destiny: Social conditioning? Best Practice \& Research Clinical Obstetrics and Gynaecology 21(1): 101-112.

de Lacey, Sheryl. 2013. Decision making about frozen supernumerary human embryos. Human Fertility 16(1): 31-34.

DeMarco, Donald. 2009. When ethics hits the wall. National Catholic Register February 13, 2009.

Dowling-Lacey, Donna, Jacob Mayer, Estella Jones, Silvina Bocca, Laurel Stadtmauer, and Sergio Oehninger. 2011. Live birth from a frozen-thawed pronuclear stage embryo almost 20 years after its cryopreservation. Fertility and Sterility 95(3): 1120-1123.

Ellison, David, and Isabel Karpin. 2011. Embryo disposition and the new death scene. Cultural Studies Review 17(1): 81-100.

Explanatory Memorandum to the Human Fertilisation and Embryology (Statutory Storage period for Embryos and Gametes) (Amendment Regulations) 2009 No. 2581.

Franklin, Sarah. 2006. Origin stories revisited: IVF as an anthropological project. Culture, Medicine and Psychiatry 30: 547-555.

Fuscaldo, Giuliana. 2005. Spare embryos: 3000 reasons to rethink the significance of genetic relatedness. Reproductive Biomedicine Online 10(2): 164-168. 
Go, Katherine, Stephen Corson, Frances Batzer Frances, and J.L. Walters. 1998. Live birth from a zygote cryopreserved for 8 years. Human Reproduction 13(1): 2970-2971.

Goedeke, Sonja, and Deborah Payne. 2009. Embryo donation in New Zealand: A pilot study. Human Reproduction 1(1): 1-7.

Gook, Debra, and David Edgar. 1999. Cryopreservation of the human female gamete: Current and future issues. Human Reproduction 14(12): 2938-2940.

Greenhouse, Carol J. 1989. Just in time: Temporality and the cultural legitimation of law. Yale Law Journal 98: 1631-1651.

Hallowell, Irving A. 1937. Temporal orientation in western civilization and in a pre-literate society. American Anthropologist 39: 647-670.

Haraway, Donna J. 1991. Simians, Cyborgs, and Women: The reinvention of nature. New York: Routledge.

Harrington, John. 2012. Time as a dimension of medical law. Medical Law Review 20: 491-515.

Hogle, Linda. 2001. Life/time warranty. In Rethinking life and death, ed. Sarah Franklin and Margaret Lock, 97-128. London: School of American Research Press.

Jackson, Emily. 2006. Fraudulent stem cell research and respect for the embryo. BioSocieties 1(3): 349-356.

Jackson, Emily. 2008. Degendering reproduction? Medical Law Review 16: 346-363.

Jacob, Marie-Andrée, and Barbara Prainsack. 2010. Embryonic hopes: Controversy, alliance and reproductive entities in law and the social sciences. Social and Legal Studies 19(4): 497-498.

Jasanoff, Sheila. 2004. Ordering knowledge, ordering society. In States of knowledge: The co-production of science and social order, ed. Sheila Jassanoff, 13-45. London and New York: Routledge.

Jasanoff, Sheila. 2012. Science and public reason. United States: Routledge.

Karpin, Isabel, Jenni Millbank, Anita Stuhmcke, and Eloise Chandler. 2013. Analysing IVF participant understanding of, involvement in, and control over embryo storage and destruction in Australia. Journal of Law and Medicine 20: 811-821.

Kirkman, Maggie. 2008. Being a "Real" mum: Motherhood through donated eggs and embryos. Women's Studies International Forum 31: 241-248.

Klock, Susan, Sandra Sheinin, and Ralph Kazer. 2001. The disposition of unused frozen embryos. New England Journal of Medicine 345: 69-70.

Kovacs, Gabor T., Sue A. Breheny, and Melinda J. Dear. 2003. Embryo donation at an Australian university in vitro fertilisation clinic: issues and outcomes. Medical Journal of Australia 178: 127-129.

Kuo, Lee. 1996-1997. Lessons learned from Great Britain's Human Fertilization and Embryology Act: Should the United States regulate the fate of unused frozen embryos? Loy. L.A. Int'l Comp. LJ. 19: 1027-1053.

Lanzendorf, Susan, Valerie Ratts, Sarah Keller, and Randall Odem. 2010. Disposition of cryopreserved embryos by infertility patients desiring to discontinue storage. Fertility and Sterility 93(2): 486-489.

Law and Ethics Taskforce of the European Society for Human Reproduction and Embryology (ESHRE). 2001. Task force on ethics and law II: The cryopreservation of human embryos. Human Reproduction 16: 1049.

Lorio, Kathryn V. 1996. From Cradle to Tomb: Estate planning considerations of the new procreation. Louisiana Law Review 57: 27-52.

Lyerly, Anne D., Karen Steinhauser, Emily Namey, James A. Tulsky, Robert Cook-Deegan, Jeremy Sugarman, David Walmer, Ruth Fadden, and Edward Wallach. 2006. Factors that affect infertility patients' decisions about disposition of frozen embryos. Fertility and Sterility 85: 1623-1630.

Lyerly, Anne D., Karen Steinhauser, Corrine Voils, Emily Namey, Carolyn Alexander, Brandon Bankowski, Robert Cook-Deegan, William C. Dodson, Elena Gates, Emily S. Jungheim, Peter G. McGovern, Evan R. Mayers, BarbaraOsborn Osborn, William Schalff, Jeremy Sugarman, James Tulsky, David Walmer, Ruth Fadden, and Edward Wallach. 2008. Fertility patients' views about frozen embryo disposition: results of a multi-institutional U.S. survey. Fertility and Sterility 93: 499-509.

Magli, Cristina M., Etienne Van den Abbeel, Kersti Lundin, Dominique Royere, J. Van der Elst, and L. Gianaroli. 2008. Revised guidelines for good practice in IVF laboratories. Human Reproduction 23(6): 1253-1262.

Mandelbaum, Jacqueline, Joelle Belaisch-Allart, Anne-Marie Junca, Jean-Marie Antione, Michelle Plachot, Sylvia Alvarez, Marie-Odile Alnot, and Jacaues Salat-Baroux. 2011. Cryopreservation in 
human assisted reproduction is now routine for embryos but remains a research procedure for oocytes. Human Reproduction 13(3): 161-174.

McMahon, Catherine, Frances Gibson, Garth Leslie, Jennifer Cohen, Christopher Tennant, and Douglas Saunders. 2000. Mothers conceiving through in vitro fertilization: Siblings, setbacks and embryo dilemmas after five years. Reproductive Technology Fertility and Sterility 63: 1047-1050.

Michelmann, Hans, and Penelope Nayudu. 2006. Crypreservation of human embryos. Cell and Tissue Banking 7: 135-141.

Millbank, Jenni, Anita Stuhmcke, Isabel Karpin, and Eloise Chandler. 2013. Enhancing reproductive opportunity: A study of decision-making concerning stored embryos. Sydney: UTS Printing. http:// www.allabouttheembryo.net/

Mulkay, Michael. 1994. The triumph of the pre-embryo: Interpretations of the human embryo in parliamentary debate over embryo research. Social Studies of Science 24: 611-639.

Munn, Nancy D. 1992. The cultural anthropology of time: A critical essay. Annual Review of Anthropology 21: 93-123.

Nachtigall, Robert, Gay Becker, Carrie Friese, Anneliese Butler, and Kirstin MacDougall. 2005. Parents conceptualization of their frozen embryos complicates the disposition decision. Fertility and Sterility 84(2): 431-434.

Nachtigall, Robert, Kirstin MacDougall, Jennifer Harrington, Julie Duff, Matthew Lee, and Gay Becker. 2009. How couples who have undergone in vitro fertilization decide what to do with surplus frozen embryos. Fertility and Sterility 92: 2094-2096.

National Health and Medical Research Council. 1982. Supplementary Note 4-In-vitro fertilisation and embryo transfer. Commonwealth Government Printing.

NSW Law Reform Commission. 1988. Artificial Conception: In Vitro fertilization. NSW Government Printers.

Parliamentary Office of Science and Technology. 2002. Stem Cell Research March 2002, Number 174.

Provoost, Veerle, Guido Pennings, Petra De Sutter, Jan Gerris, Annaleen Van de Velde, and Marc Dhont. 2010. Patients conceptualisation of cryopreserved embryos used in fertility treatment. Human Reproduction 25: 705-713.

Provoost, Veerle, Guido Pennings, Petra De Sutter, and Marc Dohnt. 2012. "Something of the two of us". The emotionally loaded embryo disposition decision making of patients who view their embryo as a symbol of their relationship. Journal of Pscyhosomatic Obstetrics and Gyneacology 33(2): 52.

Report of the Committee of Inquiry into Human Fertilisation and Embryology. 1984. United Kingdom, Department of Health and Social Security, (Warnock Committee Report).

Riggs, Ryan, Jacob Mayer, Donna Dowling-Lacey, Ting-Fing Chi, Estella Jones, and Sergio Oehninger. 2010. Does storage time influence posthaw, survival and pregnancy outcome? An analysis of 11,768 cryopreserved human embryos. Fertility and Sterility 93(1): 109-115.

Roberts, Elizabeth F.S. 2007. The ethics of cryopreservation in Ecuador and elsewhere. American Ethnologist 34(1): 181-199.

Roberts, Elizabeth. 2011. Abandonment and accumulation: Embryonic futures in the United States and Ecuador. Medical Anthropology Quarterly 25(2): 232-253.

Robertson, John A. 1990. In the beginning: The legal status of early embryos. Virginia Law Review 76: 437-495.

Rosenwaks, Zev, and Owen Davis. 1997. On the destruction of cryopreserved human embryos: An opinion. Human Reproduction 12(6): 1121-1124.

Saunders, Douglas, Mark Bowman, Alexandra F. Grierson, and Felicity Garner. 1995. Frozen embryos: Too cold to touch? Human Reproduction 10(12): 3081.

Scott, Rosamund, Clare Williams, Kathryn Ehrich, and Bobbie Farsides. 2012. Donation of 'spare' fresh or frozen embryos to research: Who decides that an embryo is 'spare' and how can we enhance the quality and protect the validity of consent? Medical Law Review 20(3): 255-303.

Sheldon, Sally. 2004. Evans v Amicus Health Care: Revealing cracks in the "Twin Pillars"? Child and Family Law Quarterly 16: 437-452.

Simpson, Bob. 2006. Scrambling parenthood. Anthropology Today 22(3): 3-6.

Stewart, Pam, and Anita Stuhmcke. 2007. Legal pragmatism and the prebirth continuum. Journal of Law and Medicine 15(2): 272-295.

Stuhmcke, Anita, and Eloise Chandler. 2014. Storage limits of gametes and embryos: Regulation in search of policy justification. Journal of Law and Medicine 22: 121-135. 
The practice committees of the American Society for Reproductive Medicine and the Society for Assisted Reproductive Technology. 2013. Mature oocyte cryopreservation: A guideline. Fertility and Sterility 99(1): 37.

Thomas, Lynne M. 1997-1998. Abandoned frozen embryos and Texas law of abandoned personal property: Should there be a connection? St. Mary's Law Journal 29: 255-314.

Trounson, Alan, and Linda Mohr. 1983. Human pregnancy following cryopreservation, thawing and transfer of an eight-cell embryo. Nature 305: 707-709.

Veeck, Lucinda. 1997. Frozen preimplantation embryos: parental responsibility versus laboratory liability. Human Reproduction 12(6): 1121-1124.

Wang, X.J., W. Ledger, D. Payne, R. Jeffrey, and C.D. Matthews. 1994. The contribution of embryo cryopreservation to in vitro fertilization/gamete intra-fallopian transfer: 8 years experience. Human Reproduction 9(1): 103-109.

Western Australia Reproductive Technology Council. 2010. Policy on embryo storage and applications to extend storage beyond ten years.

Western Australian Reproductive Technology Council. 2012. Annual Report. 